\title{
The Prevalence of Autoantibodies in Saudis Patients with Type 1 Diabetes Mellitus"
}

\author{
K. S. Aljabri ${ }^{1 \#}$, S. A. Bokhari ${ }^{1}$, K. Alqurashi ${ }^{2}$ \\ ${ }^{1}$ Department of Endocrinology, King Fahad Armed Forces Hospital, Jeddah, KSA \\ ${ }^{2}$ Department of Primary Care, King Fahad Armed Forces Hospital, Jeddah, KSA \\ Email: "khalidsaljabri@yahoo.com
}

Received January 6, 2013; revised February 6, 2013; accepted March 6, 2013

Copyright (C) 2013 K. S. Aljabri et al. This is an open access article distributed under the Creative Commons Attribution License, which permits unrestricted use, distribution, and reproduction in any medium, provided the original work is properly cited.

\begin{abstract}
Background: Type 1 Diabetes mellitus (T1DM) results from a cellular-mediated autoimmune destruction of the $\beta$-cells of the pancreas. We designed this study to determine the prevalence of autoantibodies among Saudis patients with T1DM. Methods: Glutamic acid decarboxylase antibodies (GADA), antibodies to Islet cell (ICA) and Insulin (IAA) were measured in 171 Saudis patients with T1DM. Results: There were 171 patients with T1DM, 71 males (41.5\%) and 100 females $(58.5 \%)$. The mean age was $20.8 \pm 6.6$ and the mean diabetes duration was $7.7 \pm 5.7$. GADA, ICA and IAA were detected in $53.8 \%, 32.2 \%$ and $76 \%$ respectively. GADA, ICA and IAA were nonsignificantly more frequent in female and GADA and IAA were significantly more frequent in those younger than 20 years of age. Subjects testing positive for GADA had higher levels of ICA $(42.4 \%$ vs. $20.3, \mathrm{p}=0.003)$ and IAA $(79.3 \%$ vs. $72.2, \mathrm{p}=0.3)$ than those negative for GADA. Multiple antibodies $(\geq 2)$ were observed more often in patients under the age of 20 years. There were nonsignificant differences in the prevalence of multiple antibodies between both genders. Multiple logistic regression analysis showed a significant independent positive relationship between the serum positivity of GADA, ICA and Multiple antibodies $(\geq 2)$ with diabetes duration $(0.02, p=0.03,0.02, p=0.01$ and $0.01, p=0.04$ respectively). Conclusions: The prevalence of autoantibodies in Saudi patients with T1DM is similar to those reported for diabetic patients in other ethnic groups.
\end{abstract}

Keywords: Type 1 Diabetes Mellitus; Autoantibodies; Prevalence; Saudi Arabia

\section{Introduction}

Type I diabetes mellitus (T1DM) is closely related to both cellular and humoral immune responses to insulinproducing beta cells [1]. Antibodies to glutamic acid decarboxylase (GADA) and Islet cell antibodies (ICA) have been observed to persist after the clinical diagnosis of Type I diabetes, and with highly fluctuating concentrations for GADA [2,3]. Studies in Caucasian populations have revealed an $80 \%$ - $90 \%$ occurrence of autoantibodies in patients newly diagnosed with T1DM [4,5]. Reports from Asia have demonstrated an $83 \%$ - 90\% occurrence of GADA in Japanese patients with T1DM [6]. However earlier studies in the 1980's reported an occurrence as low as $7 \%$ of islet cell autoantibodies ICA in Japanese patients with T1DM and around a $40 \%$ occurrence in a mixed Asian population with T1DM in Singapore [7-9]. Studies in Africa in the same period indicated

\footnotetext{
*Declaration of Competing Interests: Nothing to declare.
}

\#Corresponding author. an occurrence of ICA ranging from 7\%-9\% in patients with T1DM from Nigeria and Tanzania, 36\% - 44\% in patients with T1DM from South Africa, and $43 \%$ in patients from Ethiopia [10-14]. Studies in African Americans with newly diagnosed Type 1 diabetes also report a low ICA prevalence compared with that reported in Caucasian populations with T1DM $[15,16]$. There is little information on markers of autoimmune diabetes in Arab populations [17-19].

We conducted a cross section study to evaluate the relationship of the frequency of the different antibodies to sex and age of patients with T1DM from the diabetic centre at King Fahad Armed Forces Hospital and to compare these results with the prevalence of autoantibodies reported in other studies in different populations.

\section{Methods}

We tested 171 sera from patients with TIDM. These patients were recruited through the Diabetes Centre at King 
Fahad Armed Forces Hospital between January 2008 and June 2009. Eligible patients were older than 12 years old with diabetes duration of more than one year, the patients were divided into two groups according to the current age: $<20$ and $\geq 20$ years of age, and according to the current duration of diabetes: $<7$ and $\geq 7$ years. All the patients gave their or their guardian informed consent prior to their inclusion. The study was approved by the ethical board of King Fahad Armed Forces Hospital. Eligible patients met with investigators before the start of the study for a complete history and physical examination, to have laboratory assessments including GADA, ICA and IAA. Serum glutamic acid decarboxylase antibodies levels were estimated by radioimmunoassays at the reference Bioscientia Laboratory, Ingelheim, Germany, normal reference range was $<0.9 \mathrm{U} / \mathrm{mL}$. Serum islet cell antibodies levels were estimated by indirect immunoflourescence at the reference Bioscientia Laboratory, Ingelheim, Germany, normal reference range was $<1: 10$ titer. Serum insulin autoantibodies levels were estimated by radioimmunoassays at the reference Bioscientia Laboratory, Ingelheim, Germany, normal reference range was $<0.4 \mathrm{U} / \mathrm{mL}$.

\section{Statistical Analysis}

Unpaired t-test was employed to compare single parameters between groups. Chi square $\left(\mathrm{X}^{2}\right)$ test were used for categorical data comparison. Logistic regression analysis was used to examine the effects of sex, age and diabetes duration on the prevalence of the different antibodies. All statistical analyses were performed using SPSS Version 17.0. All $\mathrm{p}$ values were based on two-sided tests. The difference between groups was considered significant when $\mathrm{p}<0.05$.

\section{Results}

There were 171 patients with type 1 diabetes mellitus, 71 males $(41.5 \%)$ and 100 females $(58.5 \%)$. The mean age was $20.8 \pm 6.6$ and the mean diabetes duration was $7.7 \pm$ 5.7. GADA, ICA and IAA were detected in $53.8 \%$, $32.2 \%$ and $76 \%$ respectively, Table 1 . GADA, ICA and IAA were nonsignificantly more frequent in female and GADA and IAA were significantly more frequent in those younger than 20 years of age, Table 2. Multiple antibodies $(\geq 2)$ were observed more often in patients under the age of 20 years, $\mathrm{p}=0.009$. GADA was significantly more frequent in patients with diabetes duration less than 7 years. Subjects testing positive for GADA had higher prevalence of ICA (42.4\% vs. $20.3, p=0.003)$ and IAA $(79.3 \%$ vs. $72.2, p=0.3)$ than those negative for GADA. The mean age was nonsignificantly more younger in those with positive GADA, ICA, IAA and multiple antibodies $(\geq 2)$, Table 3 . The mean duration of diabetes were significantly shorter in those with positive GADA, ICA and multiple antibodies $(\geq 2)$, Table 3. There were persistent decline in the prevalence of GADA, ICA and IAA with the longer the diabetes duration, Figure 1. There were nonsignificant fall in prevalence of all autoantibodies in both sex over the age of 20 and with longer diabetes duration, Figure 2. Multiple logistic regression analysis showed a significant independent positive relationship between the serum positivity of GADA, ICA and Multiple antibodies $(\geq 2)$ with diabetes duration $(0.02, \mathrm{p}=0.03,0.02, \mathrm{p}=0.01$ and $0.01, \mathrm{p}=0.04$ respectively).

\section{Discussion}

Autoantibodies, reflecting activation of the immune system and $\beta$-cell response, are used diagnostically in a variety of diseases to establish whether or not the disease is autoimmune in nature. This is the case with diabetes. Current classification of diabetes endorsed by both the American Diabetes Association is based on etiopathogenesis [20]. The two major classifications of diabetes

Table 1. Prevalence of antibodies by the gender. Data are number (\%).

\begin{tabular}{ccccc}
\hline Parameters & Total & Male & Female & p value \\
\hline Number & 171 & $71(41.5)$ & $100(58.5)$ & \\
GADA & $92(53.8)$ & $38(53.5)$ & $54(54)$ & 1.0 \\
ICA & $55(32.2)$ & $20(28.2)$ & $35(35)$ & 0.4 \\
IAA & $130(76)$ & $52(73.2)$ & $78(78)$ & 0.5 \\
One & $57(33.3)$ & $28(39.4)$ & $29(29)$ & 0.2 \\
Two & $65(38)$ & $23(32.4)$ & $42(42)$ & 0.3 \\
Three & $30(17.5)$ & $12(16.9)$ & $18(18)$ & 1.0 \\
None & $19(11.1)$ & $8(11.3)$ & $11(11)$ & 1.0 \\
Antibodies $(\geq 2)$ & $95(55.6)$ & $35(49.3)$ & $60(60)$ & 0.2 \\
\hline
\end{tabular}


Table 2. Prevalence of antibodies by the age and diabetes duration.

\begin{tabular}{|c|c|c|c|c|c|c|}
\hline \multirow{2}{*}{ Autoantibodies } & \multicolumn{3}{|c|}{ Age (years) } & \multicolumn{3}{|c|}{ Diabetes duration (years) } \\
\hline & $<\mathbf{2 0}$ & $\geq 20$ & p value & $<7$ & $\geq 7$ & p value \\
\hline GADA & $54(64)$ & $38(44)$ & 0.01 & $52(63)$ & $40(46)$ & 0.03 \\
\hline ICA & $30(35)$ & $25(29)$ & 0.4 & $31(37)$ & $24(27)$ & 0.2 \\
\hline IAA & $71(84)$ & $59(69)$ & 0.03 & $60(73)$ & $70(80)$ & 0.3 \\
\hline One $^{*}$ & $24(28)$ & $33(38)$ & 0.2 & $22(27)$ & $35(40)$ & 0.08 \\
\hline Two* & $37(44)$ & $28(33)$ & 0.2 & $32(39)$ & $33(38)$ & 1.0 \\
\hline Three* & $19(22)$ & $11(13)$ & 0.1 & $19(23)$ & $11(13)$ & 0.1 \\
\hline None $^{*}$ & $5(6)$ & $14(16)$ & 0.05 & $10(12)$ & $9(12)$ & 0.8 \\
\hline Antibodies $(\geq 2)$ & $56(66)$ & $39(45)$ & 0.009 & $51(61)$ & $44(50)$ & 0.2 \\
\hline
\end{tabular}

Data are number $(\%) .{ }^{*}$ Means number of autoantibodies types detected.

Table 3. The mean \pm standard deviation of age and diabetes duration according to the autoantibodies.

\begin{tabular}{|c|c|c|c|c|c|}
\hline \multicolumn{2}{|c|}{ Antibodies } & \multirow{3}{*}{$\begin{array}{c}\text { Age (years) } \\
20.3 \pm 7.0 \\
21.4 \pm 6.0\end{array}$} & \multirow{3}{*}{$\begin{array}{c}\text { p values } \\
0.3\end{array}$} & \multirow{3}{*}{$\begin{array}{c}\text { Diabetes duration (years) } \\
6.8 \pm 5.1 \\
8.7 \pm 6.1\end{array}$} & \multirow{3}{*}{$\begin{array}{c}\text { p values } \\
0.03\end{array}$} \\
\hline \multirow{2}{*}{ GADA } & Present & & & & \\
\hline & Absent & & & & \\
\hline \multirow{2}{*}{ ICA } & Present & $20.3 \pm 6.8$ & \multirow{2}{*}{0.5} & $6.1 \pm 4.5$ & \multirow{2}{*}{0.01} \\
\hline & Absent & $20.0 \pm 6.5$ & & $8.4 \pm 6.0$ & \\
\hline \multirow{2}{*}{ IAA } & Present & $20.3 \pm 6.3$ & \multirow{2}{*}{0.08} & $7.9 \pm 5.5$ & \multirow{2}{*}{0.5} \\
\hline & Absent & $22.4 \pm 7.3$ & & $7.2 \pm 6.2$ & \\
\hline \multirow{2}{*}{ One } & Present & $21.6 \pm 6.9$ & \multirow{2}{*}{0.3} & $9.1 \pm 6.1$ & \multirow{2}{*}{0.03} \\
\hline & Absent & $20.4 \pm 6.4$ & & $7.0 \pm 5.2$ & \\
\hline \multirow{2}{*}{ Two } & Present & $19.8 \pm 5.6$ & \multirow{2}{*}{0.1} & $7.6 \pm 5.3$ & \multirow{2}{*}{0.9} \\
\hline & Absent & $21.5 \pm 5.7$ & & $7.7 \pm 5.9$ & \\
\hline \multirow{2}{*}{ Three } & Present & $20.3 \pm 7.7$ & \multirow{2}{*}{0.6} & $5.3 \pm 3.8$ & \multirow{2}{*}{0.01} \\
\hline & Absent & $20.9 \pm 6.3$ & & & \\
\hline \multirow{2}{*}{ None } & Present & $23.0 \pm 6.3$ & \multirow{2}{*}{0.1} & $7.6 \pm 6.8$ & \multirow{2}{*}{1.0} \\
\hline & Absent & $20.5 \pm 6.6$ & & $7.7 \pm 5.5$ & \\
\hline \multirow{2}{*}{ Antibodies ( $\geq 2$ ) } & Present & $19.9 \pm 6.3$ & \multirow{2}{*}{0.05} & $6.9 \pm 5.0$ & \multirow{2}{*}{0.04} \\
\hline & Absent & $21.9 \pm 6.7$ & & $8.7 \pm 6.3$ & \\
\hline
\end{tabular}

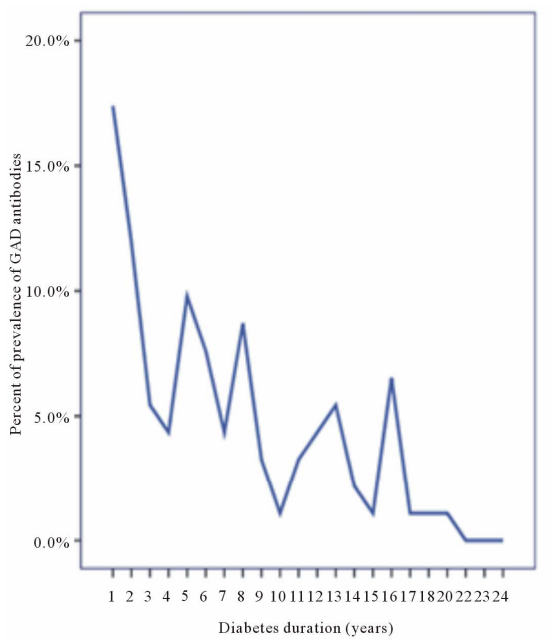

(a)

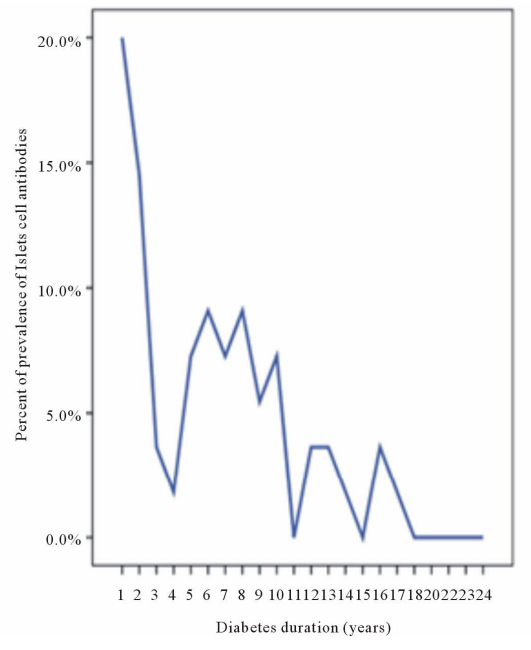

(b)

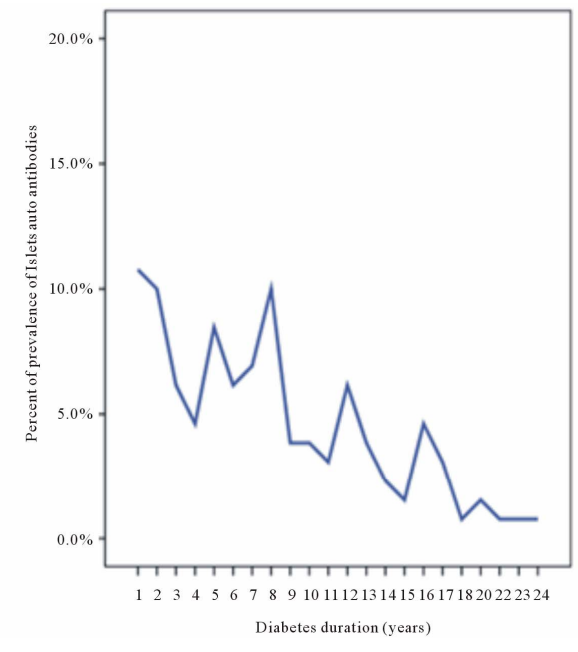

(c)

Figure 1. Prevalence of GADA, ICA and IAA with the diabetes duration. 


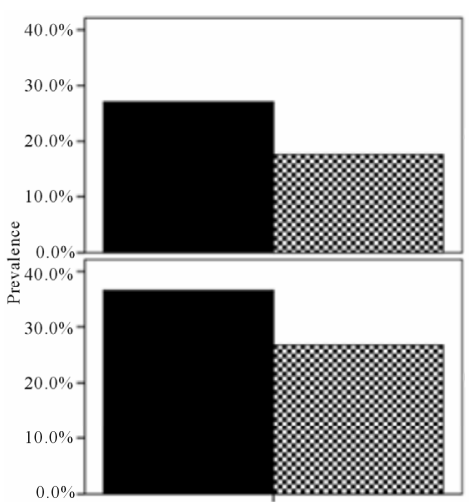

Glutamic aid decarboxylase antibodies

(a)

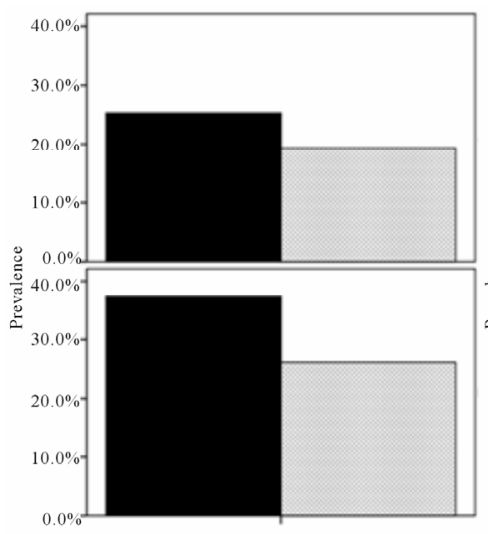

Glutamic aid decarboxylase antibodies

(d)

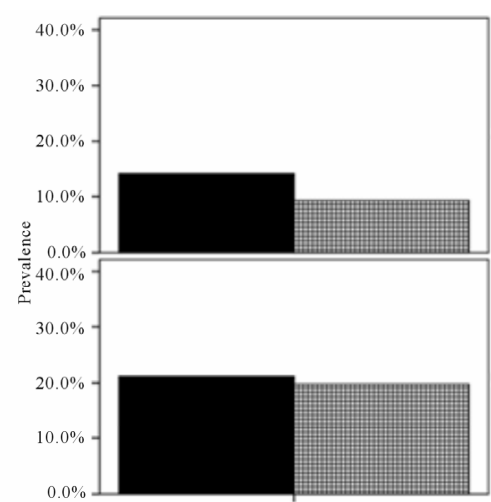

Antibodies to Islet cell

(b)

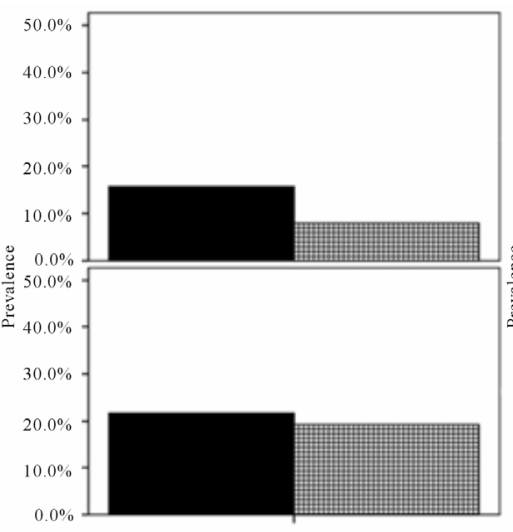

Islet cell antibodies

(e)

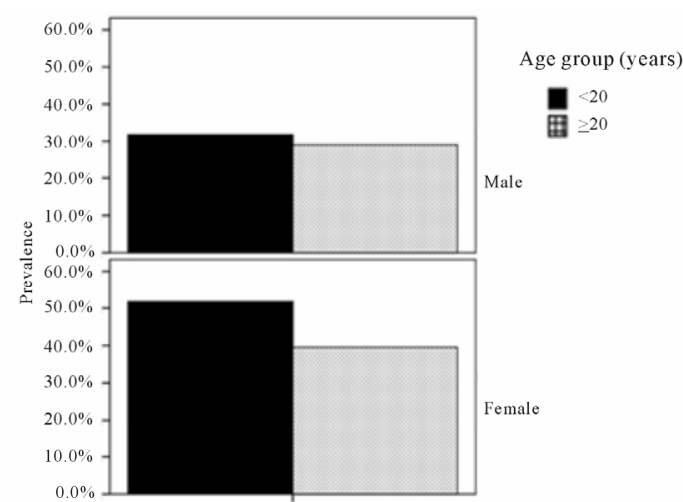

Insulin autoantibodies

(c)

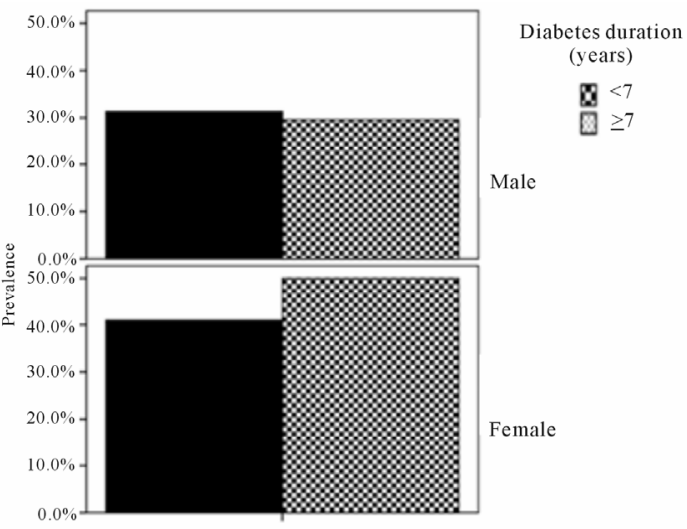

Insulin autoantibodies

(f)

Figure 2. Prevalence of all autoantibodies in both sex over the age of 20 and with diabetes duration.

are type 1 diabetes, characterized by a state of $\beta$-cell destruction, and type 2 diabetes, characterized by a combination of resistance to insulin action and an inadequate compensatory response in insulin secretion. Evidence that type 1 diabetes is an autoimmune process is most commonly based on the presence of diabetes antibodies (GADA, ICA or IAAs).

The mechanisms by which these islet autoantigenspecific autoantibodies show an age-dependent effect are not understood. Type 1 diabetes is twice as common among men in subjects $>20$ years of age [21]. However, this difference between sexes is not easily explained by the diagnostic sensitivity of the autoantibodies. The fact that the diagnostic sensitivity varies with age and sometimes with sex has important consequences when using autoantibodies to predict type 1 diabetes.

The levels of these autoantibodies are influenced by duration of diabetes, age and sex. We therefore analysed the Saudi patients in relation to these parameters. Overall, autoantibodies were more prevalent in the Saudi TIDM patients with younger age of onset. Females showed nonsignificant a higher prevalence of autoantibodies than males, as also reported in European patients [22,23].

In contrast to a previously reported, the age-related decline in the levels and prevalence of autoantibodies is unexplained [24]. Our study has revealed a fall in prevalence for all autoantibodies with older age in both sexes.

The diabetes duration-related decline in the levels and prevalence of autoantibodies were observed. Our study has revealed a fall in prevalence for all autoantibodies in both sexes in whom have diabetes duration more than 7 years. This study confirmed that GADA, ICA are inversely correlated with diabetes duration in patients with Type 1diabetes.

In conclusion, the prevalence and associations of autoantibodies in Saudi patients with T1DM are similar to those reported for diabetic patients in other ethnic groups.

\section{REFERENCES}

[1] M. Knip, "Disease-Associated Autoimmunity and Prevention of Insulin-Dependent Diabetes Mellitus," Annals of Medicine, Vol. 29, No. 5, 1997, pp. 447-451. doi: $10.3109 / 07853899708999375$ 
[2] H. Kolb, K. Dannehl and D. Gruneklee, "Prospective Analysis of Islet Cell Antibodies in Children with Type 1 (Insulindependent) Diabetes," Diabetologia, Vol. 31, No. 4, 1988, pp. 189-194. doi:10.1007/BF00290583

[3] M. R. Batstra, M. Pina, J. Quan, et al., "Fluctuations in GAD65 Antibodies after Clinical Diagnosis of IDDM in Young Children," Diabetes Care, Vol. 20, No. 4, 1997, pp. 642-644. doi:10.2337/diacare.20.4.642

[4] M. Landin-Olsson, J. P. Palmer, Å. Lernmarks, L. Blom, G. Sundkvist, L. Nystrm and G. Dahlquist, "Predictive Value of Islet Cell and Insulin Autoantibodies for Type 1 (Insulin-Dependent) Diabetes Mellitus in a PopulationBased Study of Newly-Diagnosed Diabetic and Matched Control Children," Diabetologia, Vol. 35, No. 11, 1992, pp. 1068-1073. doi:10.1007/BF02221683

[5] A. L. Notkins and A. Lernmark, "Autoimmune Type 1 Diabetes: Resolved and Unresolved Issues," Journal of Clinical Investigation, Vol. 108, No. 9, 2001, pp. 12471252.

[6] E. Kawasaki and K. Eguchi, "Is Type 1 Diabetes in the Japanese Population the Same as among Caucasians?" Annals of the New York Academy of Sciences, Vol. 1037, 2004, pp. 96-103. doi:10.1196/annals.1337.014

[7] T. Kobayashi, S. Sawano, T. Itoh, T. Sugimoto, T. Tanaka and S. Suwa, "The Prevalence of Islet-Cell Antibodies and Complement-Fixing Islet-Cell Antibodies in Japanese Diabetics," Endocrinologia Japonica, Vol. 28, No. 4, 1981, pp. 429-433. doi:10.1507/endocri1954.28.429

[8] Y. S. Lee, W. Y. Ng, A. C. Thai, K. F. Lui and K. Y. Loke, "Prevalence of ICA and GAD Antibodies at Initial Presentation of Type 1 Diabetes Mellitus in Singapore Children," Journal of Pediatric Endocrinology and Metabolism, Vol. 14, No. 6, 2001, pp. 767-772. doi:10.1515/JPEM.2001.14.6.767

[9] A. L. Todd, W. Y. Ng, K. F. Lui and A. C. Thai, "Low Prevalence of Autoimmune Diabetes Markers in a Mixed Ethnic Population of Singaporean Diabetics," Internal Medicine Journal, Vol. 34, No. 1-2, 2004, pp. 24-30. doi:10.1111/j.1444-0903.2004.00482.x

[10] D. G. McLarty, I. Athaide, G. F. Bottazzo, A. M. Swai and K. G. Alberti, "Islet Cell Antibodies Are Not Spe- cifically Associated with Insulindependent Diabetes in Tanzanian Africans," Diabetes Research and Clinical Practice, Vol. 9, No. 3, 1990, pp. 219-224. doi:10.1016/0168-8227(90)90048-X

[11] J. M. Oli, G. F. Bottazzo and D. Doniach, "Islet Cell Antibodies and Diabetes in Nigerians," Tropical and Geographical Medicine, Vol. 33, No. 2, 1981, pp. 161-164.

[12] M. A. Omar, G. Bottazzo and A. C. Asmal, "Islet Cell Antibodies and Other Autoantibodies in South African Blacks and INDIANS with Insulin Dependent Diabetes Mellitus (IDDM)," Hormone and Metabolic Research, Vol. 18, No. 2, 1986, pp. 126-128. doi:10.1055/s-2007-1012247

[13] W. H. Peters, F. T. Lester, K. D. Kohnert and W. Hildmann, "The Frequency of Islet Cell Surface Antibodies in Newly Diagnosed Diabetics from Ethiopia," Experimental and Clinical Endocrinology, Vol. 87, No. 3, 1986, pp.
326-332. doi:10.1055/s-0029-1210562

[14] V. R. Panz, W. J. Kalk, M. Zouvanis and B. I. Joffe, "Distribution of Autoantibodies to Glutamic Acid Decarboxylase across the Spectrum of Diabetes Mellitus Seen in South Africa," Diabetic Medicine, Vol. 17, No. 3, 2000, pp. 524-527. doi:10.1046/j.1464-5491.2000.00324.x

[15] M. Neufeld, N. K. Maclaren, W. J. Riley, D. Lezotte, J. V. McLaughlin, J. Silverstein and A. L. Rosenbloom, "Islet Cell and Other Organ-Specific Antibodies in U.S. Caucasians and Blacks with Insulin-Dependent Diabetes Mellitus," Diabetes, Vol. 29, 1980, pp. 589-592. doi:10.2337/diabetes.29.8.589

[16] I. M. Libman, M. Pietropaolo, M. Trucco, J. S. Dorman, R. E. LaPorte and D. Becker, "Islet Cell Autoimmunity in White and Black Children and Adolescents with IDDM," Diabetes Care, Vol. 21, No. 11, 1998, pp. 1824-1827.

[17] N. A. Kulaylat and H. Narchi, "A Twelve Year Study of the Incidence of Childhood Type 1 Diabetes Mellitus in the Eastern Province of Saudi Arabia," Journal of Pediatric Endocrinology and Metabolism, Vol. 13, No. 2, 2000, pp. 135-140.

[18] O. S. Al-Attas, M. A. Laajam and M. S. Khan, "Freqency of Islet Cell Antibodies in Adult Newly Diagnosed Diabetic Patients," Annals of Saudi Medicine, Vol. 10, 1990, pp. 369-373.

[19] L. H. Damanhouh, J. A. Dromey, M. R. Christie, H. A. Nasrat, M. S. M. Ardawi, R. A. Robins and I. Todd, "Autoantibodies to GAD and IA-2 in Saudi Arabian Diabetic Patients," Diabetic Medicine, Vol. 22, No. 4, 2005 , pp. 448-452. doi:10.1111/j.1464-5491.2005.01438.x

[20] American Diabetes Association, "Diagnosis and Classification of Diabetes Mellitus," Diabetes Care, Vol. 33, 2010, pp. S62-S69. doi:10.2337/dc10-S062

[21] G. Blohmé, L. Nyström, H. J. Arnqvist, F. Lithner, B. Littorin, P. O. Olsson, B. Scherstén, L. Wibell and J. Ostman, "Male Predominance of Type 1 (Insulin-Dependent) Diabetes Mellitus in Young Adults: Results from a 5-Year Prospective Nationwide Study of the 15 - 34-Year Age Group in Sweden," Diabetologia, Vol. 35, No. 1, 1992, pp. 56-62.

[22] W. A. Hagopian, G. B. Sanjeevi, I. Kockum, M. LandinOlsson, A. E. Karlsen, G. Sundkvist, et al., "Glutamate Decarboxylase-, Insulin-, and Islet Cell-Antibodies and HLA Typing to Detect Diabetes in a General Population-Based Study of Swedish Children," Journal of Clinical Investigation, Vol. 95, No. 4, 1995, pp. 1505-1511. doi:10.1172/JCI117822

[23] J. R. Bilbao, I. Rica, J. A. Vazquez, M. A. Busturia and L. Castano, "Influence of Sex and Age at Onset on Autoantibodies against Insulin, GAD65 and 1A2 in Recent Onset Type 1 Diabetic Patients," Hormone Research, Vol. 54, 2000, pp. 181-185. doi:10.1159/000053256

[24] A. Williams, A. Norcross, R. Dix, K. Gillespie, E. Gale and P. Bingley, "The Prevalence of Insulin Autoantibodies at the Onset of Type 1 Diabetes Is Higher in Males than Females during Adolescence," Diabetologia, Vol. 46, No. 10, 2003, pp. 1354-1356. doi:10.1007/s00125-003-1197-2 